\title{
Brassinosteroids Regulate Anthocyanin Biosynthesis in the Ripening of Grape Berries
}

\author{
L.-Y. Luan ${ }^{1}$, Z.-W. Zhang ${ }^{1,2^{*}}$, Z.-M. Xi ${ }^{1,2^{*}}$, S.-S. Huo ${ }^{1}$ and L.-N. Ma \\ (1) College of Enology, Northwest A\&F University, Yangling, 712100, China \\ (2) Shaanxi Engineering Research Centre for Viti-Viniculture, Yangling, 712100, China
}

Submitted for publication: January 2013

Accepted for publication: May 2013

Key words: Grape, anthocyanin, plant hormone, brassinosteroid, quantitative-PCR

\begin{abstract}
Anthocyanins are important components in the skins of grapes and in the development of wine colour. Various environmental factors cause poor coloration in some areas, even for the same cultivars planted in different production areas. The objective of this study was to evaluate the effect of exogenous brassinosteroids (BR) on the accumulation of anthocyanins and gene expression of anthocyanin biosynthesis in wine grape berry skins. The results show that total anthocyanin content in BR-treated grapes was higher than that in the control (CT) grapes, and that $0.4 \mathrm{mg} / \mathrm{L}$ was the most effective treatment concentration. The effect of BR on downstream genes was more effective than that on upstream genes. Full coloration of BR-treated grapes was achieved seven days earlier than in the case of CT. Moreover, BR enhanced the transcript level of the downstream genes of anthocyanin biosynthesis, which caused the total anthocyanin content to increase. The induction of structural and regulatory genes of the flavonoid pathway suggests that the interrelationships between developmental and environmental signalling pathways were magnified by $B R$ treatment, which actively promoted fruit coloration, namely anthocyanin biosynthesis.
\end{abstract}

\section{INTRODUCTION}

Skin colour is one of the most important qualities used as a basis for selection in breeding programmes for wine grapes. As a result of natural hybridisation and human selection over millennia, the skin colour of grapes has become greatly diversified, such as black, red, pink, grey, white, etc. (This et al., 2007). Berry colour results from the synthesis and accumulation of a group of coloured secondary metabolites called anthocyanins, and is determined by the quantity and composition of anthocyanins. Cultivars with coloured skins accumulate anthocyanins in their skins, whereas whiteskinned cultivars do not (Boss et al., 1996a).

With regard to the wine industry, colour is crucial for quality in the production of premium red wines. The first sensorial contact with wine is usually made by visual inspection, which starts building up the consumer's perceived quality. This translates wine colour into a value of commercial and economic relevance (Castellarin et al., 2007a). The presence of anthocyanins in grape berries is important for the fermentative processes involved in wine production (Sparvoli et al., 1994), and they can interact with some aroma substances and influence wine flavour, though anthocyanins are odourless and nearly flavourless (Dufour \& Sauvaitre, 2000). As is known, the consumption of anthocyanins and other polyphenols has health benefits associated with the scavenging of free radicals and protective effects against cardiovascular diseases and so on (Liu, 2010). Red grapes and wines are particularly rich in bioavailable anthocyanins, which are rapidly absorbed as intact molecules (Bitsch et al., 2004) and delivered into the brain within minutes of their ingestion (Passamonti et al., 2005). Therefore coloration is an important factor in determining the quality of wine grapes (Mori et al., 2005).

Anthocyanins can be modulated by a variety of environmental stimuli, including developmental signals, plant hormones, and environmental stresses such as light, temperature, irrigation and so on (Boss \& Davies, 2009). All of these things have a dual outcome: on the one hand, various environmental factors cause poor coloration in some areas (Mori et al., 2005), even for the same cultivars planted in different grape production areas; and on the other hand, these environmental stimuli can be used to improve the grape coloration. There have been many kinds of classical plant hormones applied to grapes to improve coloration, such as ethylene, naphthalene acetic acid, and abscisic acid, and these have also been implicated in the control of ripening of grape berries (Ban et al., 2003; El-kereamy et al., 2003; Jeong et al., 2004; Quiroga et al., 2009). However, very little

*Corresponding authors: E-mail: zhangzhw60@nwsuaf.edu.cn; xizhumei@nwsuaf.edu.cn

Aknowledgements: This study was supported by the National Technology System for Grape Industry (CARS-30-zp-9), the Natural Science Foundation of Shaanxi Province (2011JM3004) and the Scientific Research Program of Northwest A\&F University (QN2009059). Our thanks also go to the Key Laboratory of Horticultural Plant Biology and Germplasm Innovation, Northwest Ministry of Agriculture, China 
is known about how brassinosteroids (BRs) regulate plant growth, especially in grapes.

BRs, considered as the sixth group of hormones in plants, are steroidal hormones, which are essential for normal plant growth and development such as seed germination, rhizogenesis, flowering, senescence and abscission, and they are considered as plant hormones and have pleiotropic effects (Vardhini \& Rao, 2002). Symons et al. (2006) showed that the application of BR to grape berries evidently enhanced skin coloration and the final sugar level of the flesh, and significantly promoted ripening; on the other hand, brassinazole (Brz, an inhibitor of BR biosynthesis) significantly delayed fruit ripening. Peng et al. (2011) found that jasmonate-induced anthocyanin accumulation in Arabidopsis seedlings was reduced by treatment with Brz, whereas it was enhanced by an application of epibrassinolide (epi-BL, the most active BR). So BRs are the latest plant hormones implicated in the control of berry ripening and anthocyanin accumulation. However, reports about BRs influencing the expression of anthocyanin biosynthesis genes in grapes are few. In this experiment we therefore investigated the effect of BRs on anthocyanin accumulation in wine grapes.

The pathway leading to the production of anthocyanins can be divided into two parts, the general phenylpropanoid pathway and the flavonoid pathway (Fig. 1) (for a review, see Boss et al., 1996c; Bogs et al., 2006). This pathway has been characterised in different plant species (Winkel, 2006), especially in Vitis vinifera $(V v)$, where the expression of genes involved in flavonoid synthesis (particularly anthocyanins and proanthocyanidins) has been well characterised in the berries and seeds of both red and white cultivars (Sparvoli et al., 1994; Boss et al., 1996a, 1996b; Bogs et al., 2006; Castellarin et al., 2007a).

Recently, two classes of genes affecting anthocyanin biosynthesis have been described. One class includes the structural genes of the pathway, which is common to different species, and the second class includes genes that regulate the activity of the biosynthetic genes, conditioning the spatial and temporal accumulation of pigments (Sparvoli et al., 1994). It has been shown that these regulatory genes belong to two major groups of transcription factors, namely the MYB and bHLH families (Holton \& Cornish, 1995; Sainz et al., 1997; Spelt et al., 2000; Ozeki et al., 2003; Ramsay et al., 2003; Robbins et al., 2003; Borovsky et al., 2004; Schwinn et al., 2006).

In grapes, Myb-related transcription-factor genes (such as VIMYBA1-1, VIMYBA1-2 and VIMYBA2) have been isolated from mature berries, and these Myb-related genes are involved in the regulation of anthocyanin biosynthesis in the grape via the expression of the UFGT gene (Kobayashi et al., 2002). In addition, $V v M Y B A 1$, a homolog of VIMYBA1-1 that is found in many $V$. vinifera cultivars, was shown to have the same function in anthocyanin biosynthesis as VlMYBA1-1 (Kobayashi et al., 2004, 2005). Walker et al. (2007) also found that the berry colour locus comprised two very similar genes, $V v M Y B A 1$ and $V v M Y B A 2$, and either gene could regulate colour in the grape berry. Boss et al. (1996a, 1996c) showed that the expression of UFGT was critical for anthocyanin biosynthesis in grapes. These results point out
General

Phenylpropanoid

Pathway

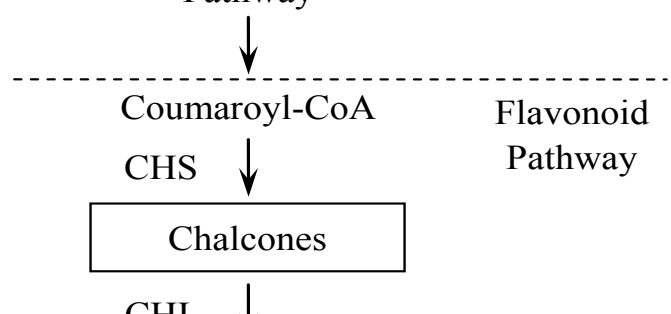

$\mathrm{CHI}$

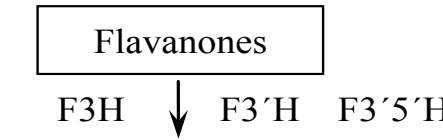

Dihydroflavonols

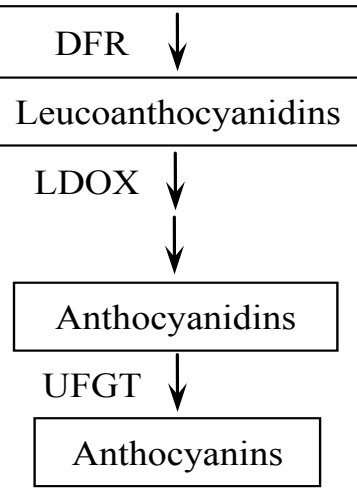

FIGURE 1

Key steps in the flavonoid pathway leading to the synthesis of anthocyanins. The enzymes involved in the pathway are as follows: $C H S$, chalcone synthase; $C H I$, chalcone isomerase; $F 3^{\prime} H$, flavonoid-3'-hydroxylase; $F 3^{\prime} 5^{\prime} H$, flavonoid3',5'-hydroxylase; $F 3 H$, flavanone-3 $\beta$-hydroxylase; $D F R$, dihydroflavonol-4-reductase; $L D O X$, leucoanthocyanidin dioxygenase; UFGT, UDP-Glc: flavonoid-3-O-glucosyltransferase.

the key role of the $V v M Y B A 1$ and $V v M Y B A 2$ transcription factors that specifically regulate the expression of $U F G T$, which encodes an enzyme responsible for the conversion of anthocyanidins to anthocyanins. Therefore, MYBAl and $M Y B A 2$ are essential for the development of coloration in ripening grape berries.

The genes of anthocyanin biosynthesis in grapes have been cloned, and detailed information can be found at NCBI, which enabled us to study the control mechanism of anthocyanin biosynthesis at the mRNA level. In this study, real-time quantitative polymerase chain reaction (Q-PCR) was used to determine the mRNA levels of eight structural genes (CHS, CHI, F3H, F3'H, F3'5'H, DFR, LDOX and $U F G T$ ) and two regulatory genes (MYBA1, MYBA2) of anthocyanin biosynthesis precisely, which enabled us to compare the mRNA levels of each examined gene in control (CT) and BR berry skins.

Thus, the objective of this study was to elucidate the effect of exogenous BR on anthocyanin biosynthesis and accumulation in the skins of wine grapes during ripening, and 
to unravel how BR regulates the anthocyanin biosynthesis by comparing the genes' transcript levels in BR and CT fruit. The results will provide useful information for further research on the mechanism of BR regulation of anthocyanin biosynthesis, as well as the effects of BR treatment on grape and wine qualities.

\section{MATERIALS AND METHODS \\ Treatment with BR}

The experimental vineyard was located in Jingyang county, Xianyang city, in Shaanxi Province in China. Six-year-old own-rooted $V$. vinifera 'Cabernet Sauvignon' grapevines of similar growth conditions and crop load were used in the study. The vines were spaced $0.8 \mathrm{~m}$ within rows and $2.5 \mathrm{~m}$ between rows, with the row oriented in a north-south direction. Vines were trained on a vertical shoot positioning system with a pair of wires, and shoots were trimmed manually twice, between bloom and véraison, to a height of about $1.0 \mathrm{~m}$. Four treatments, a CT and three BR solutions (2,4-epibrassinolide, Ruibio, Germany) of $0.1 \mathrm{mg} / \mathrm{L}$ (BR1), $0.4 \mathrm{mg} / \mathrm{L}(\mathrm{BR} 2)$ and $0.8 \mathrm{mg} / \mathrm{L}(\mathrm{BR} 3)$, were applied to all clusters of ten vines in a randomised complete block design with three replicates in separate vine rows. The BR solutions were prepared by dissolving $0.1 \mathrm{mg}, 0.4 \mathrm{mg}$ and $0.8 \mathrm{mg}$ BR in $10 \mathrm{~mL} \mathrm{98 \%} \mathrm{ethanol} \mathrm{(Sanpu,} \mathrm{Xian} \mathrm{of} \mathrm{China)} \mathrm{and} \mathrm{bringing}$ each of the three solutions to $1 \mathrm{~L}$ with water. Tween 80 (Bodi, Tianjin of China) was added as a wetting agent at $1 \mathrm{~mL} / \mathrm{L}$. The BR solutions were spray-applied at $10 \mathrm{~mL}$ per cluster with a hand-held sprayer until run off, pre-véraison (2011-07-02), ensuring that all berry surfaces were covered. A water/ethanol/Tween 80 spray was similarly applied to the clusters on the CT vines. Bunches at similar stages of development and at similar positions on the vine were tagged for treatment. Approximately 100 berries from at least 10 bunches at similar positions were collected at about 12-day intervals from 2 to 26 July. Once the grapes began colouring, sampling was more frequent (once a week). The skin, pulp and seeds were separated by hand immediately, then frozen in liquid nitrogen and stored at $-80^{\circ} \mathrm{C}$ until use.

\section{Determination of sugar and anthocyanin content}

Samples for soluble sugar measurements were pressed. The soluble sugar was determined in juice by the standard (GB/T 15038-2006). The corresponding sample of 20 berries was peeled, and the skins were immediately frozen in liquid nitrogen. After being finely powdered, one aliquot of $1.0 \mathrm{~g}$ was used for anthocyanin analyses, and one aliquot of $0.3 \mathrm{~g}$ was used for RNA extraction.

Total anthocyanins were extracted according to the method of Meng et al. (2012). Each grape extract was diluted with methanol solution and absorbance was measured at $530 \mathrm{~nm}$. The anthocyanin content (expressed in terms of cyanidin-3-glucoside) was calculated according to the method of Tang (2009).

\section{RNA extraction and quantification of mRNA}

Total RNA was extracted from the grape skins following the procedure described in Reid et al. (2006). The quality of RNA was verified by demonstration of intact ribosomal bands following agarose gel electrophoresis in addition to the absorbance ratios (A260/280) of 1.8 to 2.0. For cDNA synthesis, one microgram of total RNA was reverse transcribed using the kit of TaKaRa (Dalian, China), according to the manufacturer's instructions.

Q-PCR was carried out using the kit of TaKaRa (Dalian, China) in a iQ5 ${ }^{\mathrm{TM}}$ sequence detector (Bio-Rad, America), and the primers were synthesised by Shanghai Sunny Biotechnology Co., China. Keeping the total reaction

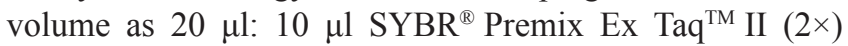
(TaKaRa, Dalian of China), $1 \mu$ F Forward Primer $(10 \mu \mathrm{M})$, $1 \mu \mathrm{l}$ Reverse Primer $(10 \mu \mathrm{M}), 1 \mu \mathrm{l} \mathrm{cDNA}, 7 \mu \mathrm{l} \mathrm{dH}_{2} \mathrm{O}$. The thermal cycling conditions were $95^{\circ} \mathrm{C}$ for $3 \mathrm{~min}$, followed by $95^{\circ} \mathrm{C}$ for $5 \mathrm{~s}$ and $60^{\circ} \mathrm{C}$ for $30 \mathrm{~s}$ for 45 cycles, followed by a melting cycle from $60^{\circ} \mathrm{C}$ to $95^{\circ} \mathrm{C}$. $G A P D H(m)$ was chosen as the reference gene, since its expression levels remained constant throughout the experiments (Reid et al., 2006). All samples were measured in triplicate, and every run included the GAPDH control for each sample. Relative expression was determined by normalising the values to that of $G A P D H$. The difference between the cycle threshold $(\mathrm{Ct})$ of the target gene and that of $G A P D H$ was used to obtain the normalised expression of the target genes (Bogs et al., 2005). Primer pairs for Q-PCR were designed based on the coding sequences available in NCBI, and some were retrieved from the literature. Primer pairs for $C H S, F 3^{\prime} H, F 3^{\prime} 5^{\prime} H, D F R$ and $L D O X$ were from Sinilal et al. (2011); primers for $F 3 H$ were from Castellarin et al. (2007a); for $U F G T$ were from Goto-Yamamoto et al. (2002); and for MYBA1 were from Jeong et al. (2004). Primers for $C H I$ and $M Y B A 2$ were newly designed to amplify 100 to $200 \mathrm{bp}$ gene fragments (Table 1).

\section{Statistical analysis}

Statistical analyses were conducted with the statistical software ANOVA (SPSS 16 for Windows), followed by a Duncan multiple range test to determine significant differences with regard to all parameters. Values were considered statistically significant at $\mathrm{P}<0.05$.

\section{RESULTS AND DISCUSSION}

\section{Accumulation of anthocyanins under BR treatments}

In this study, the last time-point before an accumulation of sugar is recorded was taken as the working definition of véraison (Davies \& Böttcher, 2009). The véraison of Cabernet Sauvignon in 2011 commenced around 15 July,

TABLE 1

Primers for genes of anthocyanin biosynthesis newly designed in this work.

\begin{tabular}{llcc}
\hline Gene & Sequence & Forward primer & Reverse primer \\
\hline CHI & X75963 & CACAGCCATCGGAGTGTACT & CTTGTCTGAATACTGGCGAC \\
MYBA2 & AB097924 & CGAGCAGGGTTGAATAGATG & CTACCCGCAATCAAGGAC \\
\hline
\end{tabular}


and according to the record of berry coloration in ripening made by visual inspection, the CT grapes began to colour on 26 July.

Fig. 2 and Table 2 show the effects of the BR1, BR2 and BR3 treatments on the accumulation of soluble sugar in berry juices during the ripening stage. The accumulation of sugar started at véraison, and it was enhanced by all BR treatments. The patterns of sugar accumulation were similar in all treatments (except BR1) (Fig. 2). Before the rapid accumulation of anthocyanins, the sugar content of these treatments was BR1 > BR2 > BR3; after that, the content was $\mathrm{BR} 2>\mathrm{BR} 3>\mathrm{BR} 1$. At harvest, the highest sugar content was $166.71 \mathrm{mg} / \mathrm{L}$ (BR2), and the lowest was 159.46 $\mathrm{mg} / \mathrm{L}$ (CT).

Fig. 3 and Table 3 show the effects of the BR1, BR2 and BR3 treatments on the anthocyanin accumulation in the skins of the grapes during the ripening stage. The accumulation of anthocyanins lagged significantly behind that of soluble sugar; it was also enhanced by all BR treatments. The patterns of anthocyanin accumulation were similar in all treatments, and the content of these treatments was BR2 $>$ BR3 $>$ BR 1 (Fig. 3). The highest anthocyanin content was $3.91 \mathrm{mg} / \mathrm{g}$ (BR2), and the lowest was $3.37 \mathrm{mg} / \mathrm{g}$ (CT).

From véraison to 9 August, the speed of sugar accumulation was fast, except during the period when anthocyanins accumulated most rapidly (2011-07-26 to 2011-08-02). The rapid accumulation of anthocyanins lagged behind that of soluble sugar by about 11 days. From 9 August to harvest, both sugar and anthocyanins increased more slowly. The grapes of CT were fully coloured red-purple on 2009-08-09 (the full coloration period) and fully coloured purple-black at harvest. The time when the anthocyanins of the BR2 and BR3 berries began to improve significantly was before 9 August, whereas that of BR1 was later than that. So the full coloration period advanced by seven days under the BR2 treatment, and by three to four days under the BR3 treatment, as shown in Fig. 3.

Davies and Böttcher (2009) pointed out that some metabolic activities, such as the accumulation of anthocyanins in berry skins, commence at véraison, and the anthocyanin accumulation studied by Castellarin et al. (2007b) also followed the accumulation of soluble solids. In this experiment, the pattern of anthocyanin accumulation was different, lagging behind soluble sugar accumulation (véraison) by about 11 days because of the cloudy and rainy weather during this period. Pigment accumulation was delayed when adequate sunlight was lacking, and then rapidly increased when the sunlight was adequate.

Of all the treatments, the effect of the BR2 $(0.4 \mathrm{mg} / \mathrm{L})$ treatment on the anthocyanin content was the most effective. Also, the BR2 treatment not only enhanced the total anthocyanin content, but full coloration was achieved seven days earlier than in the CT. Next, the expression of the genes of anthocyanin biosynthesis in the BR2 and $\mathrm{CT}$ grapes was examined by Q-PCR.

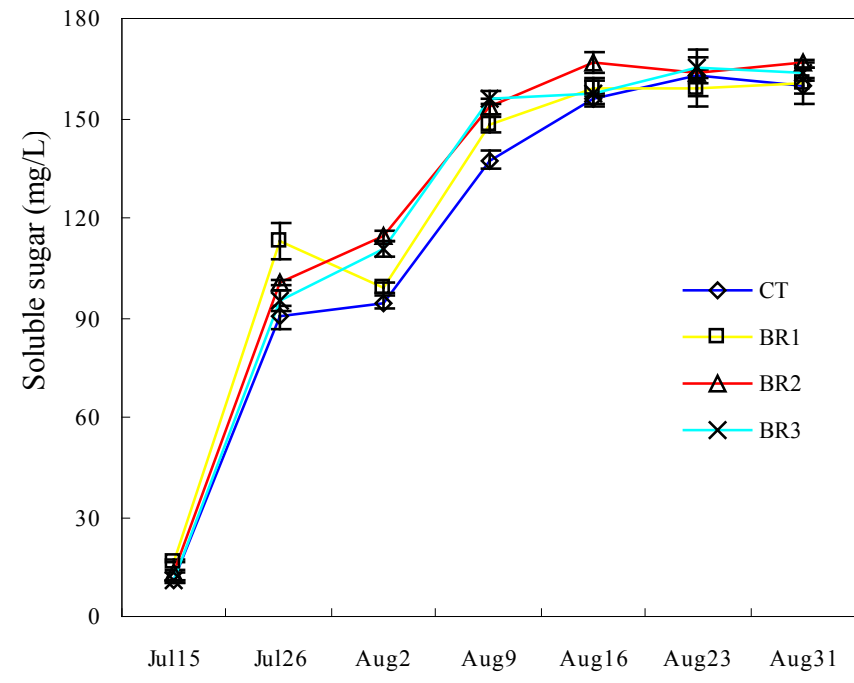

FIGURE 2

Soluble sugar concentration in the juice of grapes from the CT and BR treatments. Vertical bars represent standard deviation.

TABLE 2

Statistical analysis of soluble sugar concentration in the juice of grapes from the CT and BR treatments.

\begin{tabular}{lccccccc}
\hline & Jul 15 & Jul 26 & Aug 2 & Aug 9 & Aug 16 & Aug 23 & Aug 31 \\
\hline BR1 & $16.48 \pm 0.46^{\mathrm{a}}$ & $112.81 \pm 5.37^{\mathrm{b}}$ & $99.13 \pm 1.72^{\mathrm{c}}$ & $147.92 \pm 2.41^{\mathrm{b}}$ & $158.75 \pm 2.50^{\mathrm{b}}$ & $159.00 \pm 5.59^{\mathrm{b}}$ & $160.29 \pm 6.26^{\mathrm{cd}}$ \\
BR2 & $13.59 \pm 0.36^{\mathrm{b}}$ & $100.67 \pm 0.83^{\mathrm{c}}$ & $114.58 \pm 1.61^{\mathrm{b}}$ & $153.67 \pm 2.53^{\mathrm{a}}$ & $166.83 \pm 2.91^{\mathrm{a}}$ & $163.63 \pm 6.89^{\mathrm{ab}}$ & $166.71 \pm 1.21^{\mathrm{b}}$ \\
BR3 & $10.68 \pm 0.45^{\mathrm{d}}$ & $95.06 \pm 2.88^{\mathrm{d}}$ & $110.75 \pm 2.38^{\mathrm{b}}$ & $156.17 \pm 1.75^{\mathrm{a}}$ & $157.67 \pm 4.52^{\mathrm{bc}}$ & $165.04 \pm 3.15^{\mathrm{ab}}$ & $163.92 \pm 1.57^{\mathrm{bc}}$ \\
\hline CT & $10.72 \pm 0.23^{\mathrm{d}}$ & $90.00 \pm 3.23^{\mathrm{e}}$ & $94.50 \pm 1.80^{\mathrm{d}}$ & $137.50 \pm 2.46^{\mathrm{c}}$ & $155.58 \pm 1.65^{\mathrm{c}}$ & $162.54 \pm 2.21^{\mathrm{ab}}$ & $159.46 \pm 2.15^{\mathrm{cd}}$ \\
\hline
\end{tabular}

Notes: Data are reported as mean \pm standard deviation (SD) values; different letters (a and b) within the same column indicate significant differences at the 0.05 level by Duncan's test. 


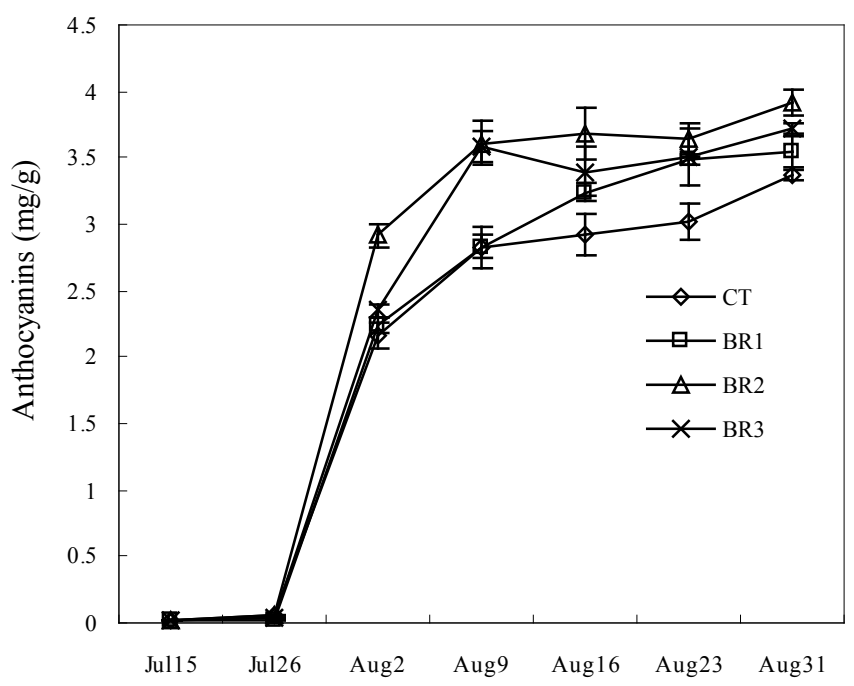

FIGURE 3

Anthocyanin concentration (fresh weight) in the skins of grapes from the CT and BR treatments. Vertical bars represent standard deviation.

TABLE 3

Statistical analysis of anthocyanin concentration in the skins of grapes from the CT and BR treatments.

\begin{tabular}{lccccccc}
\hline & Jul 15 & Jul 26 & Aug 2 & Aug 9 & Aug 16 & Aug 23 & Aug 31 \\
\hline BR1 & $0.015 \pm 0.002^{\mathrm{b}}$ & $0.023 \pm 0.002^{\mathrm{d}}$ & $2.239 \pm 0.060^{\mathrm{b}}$ & $2.833 \pm 0.083^{\mathrm{b}}$ & $3.241 \pm 0.066^{\mathrm{c}}$ & $3.478 \pm 0.036^{\mathrm{b}}$ & $3.549 \pm 0.114^{\mathrm{c}}$ \\
BR2 & $0.023 \pm 0.003^{\mathrm{a}}$ & $0.050 \pm 0.003^{\mathrm{b}}$ & $2.918 \pm 0.087^{\mathrm{a}}$ & $3.613 \pm 0.160^{\mathrm{a}}$ & $3.674 \pm 0.196^{\mathrm{ab}}$ & $3.646 \pm 0.122^{\mathrm{ab}}$ & $3.913 \pm 0.099^{\mathrm{a}}$ \\
BR3 & $0.022 \pm 0.001^{\mathrm{ab}}$ & $0.034 \pm 0.004^{\mathrm{c}}$ & $2.355 \pm 0.050^{\mathrm{b}}$ & $3.578 \pm 0.119^{\mathrm{a}}$ & $3.395 \pm 0.188^{\mathrm{bc}}$ & $3.511 \pm 0.214^{\mathrm{b}}$ & $3.716 \pm 0.044^{\mathrm{b}}$ \\
CT & $0.026 \pm 0.003^{\mathrm{a}}$ & $0.050 \pm 0.006^{\mathrm{b}}$ & $2.161 \pm 0.089^{\mathrm{b}}$ & $2.827 \pm 0.153^{\mathrm{b}}$ & $2.923 \pm 0.150^{\mathrm{d}}$ & $3.021 \pm 0.137^{\mathrm{c}}$ & $3.369 \pm 0.045^{\mathrm{d}}$ \\
\hline
\end{tabular}

Notes: Data were reported as mean \pm standard deviation (SD) values; different letters (a and b) within the same column indicate significant differences at the 0.05 level by Duncan's test.

\section{Response of structural and regulatory genes of anthocyanin biosynthesis to BR treatment}

The expression of eight structural genes of the flavonoid biosynthesis pathway ( $\mathrm{CHS}, \mathrm{CHI}, \mathrm{F3H}, \mathrm{F3} \mathrm{H}^{\prime} \mathrm{H}, \mathrm{F3} \mathrm{3}^{\prime} \mathrm{H}$, $D F R, L D O X, U F G T)$, which play a role in anthocyanin biosynthesis, and two regulatory genes (MYBA1, MYBA2) that specifically regulate $U F G T$ expression, were investigated throughout ripening by Q-PCR. All of these genes were expressed at some time during berry development (Fig. 4).

In the CT berries, $C H S, C H I, F 3^{\prime} H, D F R$ and $A N S$ were all expressed. $F 3 H$ and $F 3^{\prime} 5^{\prime} H$ were expressed at low levels and $U F G T, M Y B A 1$ and $M Y B A 2$ exhibited no expression before the colour-change period (2011-07-26). On 26 July, an increase in transcript level was observed for all the examined genes (except $F 3^{\prime} H$ ), which was coincident with changes in the colour of the grape berries. All the genes were down-regulated after full coloration (Fig. 4).

The expression of genes for anthocyanin biosynthesis was induced by the BR2 treatment (Fig. 4). In the BR berries, the expression of all examined genes was triggered before véraison. $F 3 H, F 3$ ' $H$ and $F 3^{\prime} 5^{\prime} H$ transcript levels apparently were enhanced by BR treatment and remained higher than in the CT berries at all stages. The expression peaks of $F 3 H$, $F 3^{\prime} H, F 3^{\prime} 5^{\prime} H, D F R, A N S, U F G T, M Y B A 1$ and MYBA2 advanced by 14 days in the BR berries compared to the CT berries. The rapid increase of $C H I$ expression happened on 26 July in BR, and on 2 August in CT, so it was thought to be rapidly expressed seven days in advance, and the time of high expression in BR was seven days longer than in CT. Meanwhile, the expression peak of $C H S$ also advanced by seven days (Fig. 4).

The Myb-related transcription-factor genes in grapes have been separated, and those that are involved in the regulation of anthocyanin biosynthesis via regulating the expression of UFGT (Kobayashi et al., 2002). Walker et al. (2007) found that either MYBA1 or MYBA2 can regulate colour in grape berries. In this study, similar expression patterns were observed for UFGT, MYBA1 and MYBA2. The three genes were not expressed before the colour changed and were transcribed when colour appeared in the CT berries, and they still had similar patterns (two peaks) under BR treatment (Fig. 4). Thus, the two regulatory genes had a close relationship with $U F G T$.

In the biosynthesis process from flavanones to dihydroflavonols, there are branch pathways regulated by $F 3 H, F 3^{\prime} H$ and $F 3^{\prime} 5^{\prime} H$ (Fig. 1). The genes coding for the enzymes that regulate the biosynthesis processes before flavanones in the flavonoid pathway are called upstream genes in this paper, and genes after that are called downstream genes. Then, compared with CT, all the expression peaks of the genes advanced in the BR-treated berries; those of the upstream genes by seven days, and those of the downstream genes by 14 days, so the effect of BR on the downstream genes was more pronounced. The period of full coloration was advanced by about seven days, similar to the range of the upstream genes $(\mathrm{CHI}, \mathrm{CHS})$ in the BR-treated berries. 

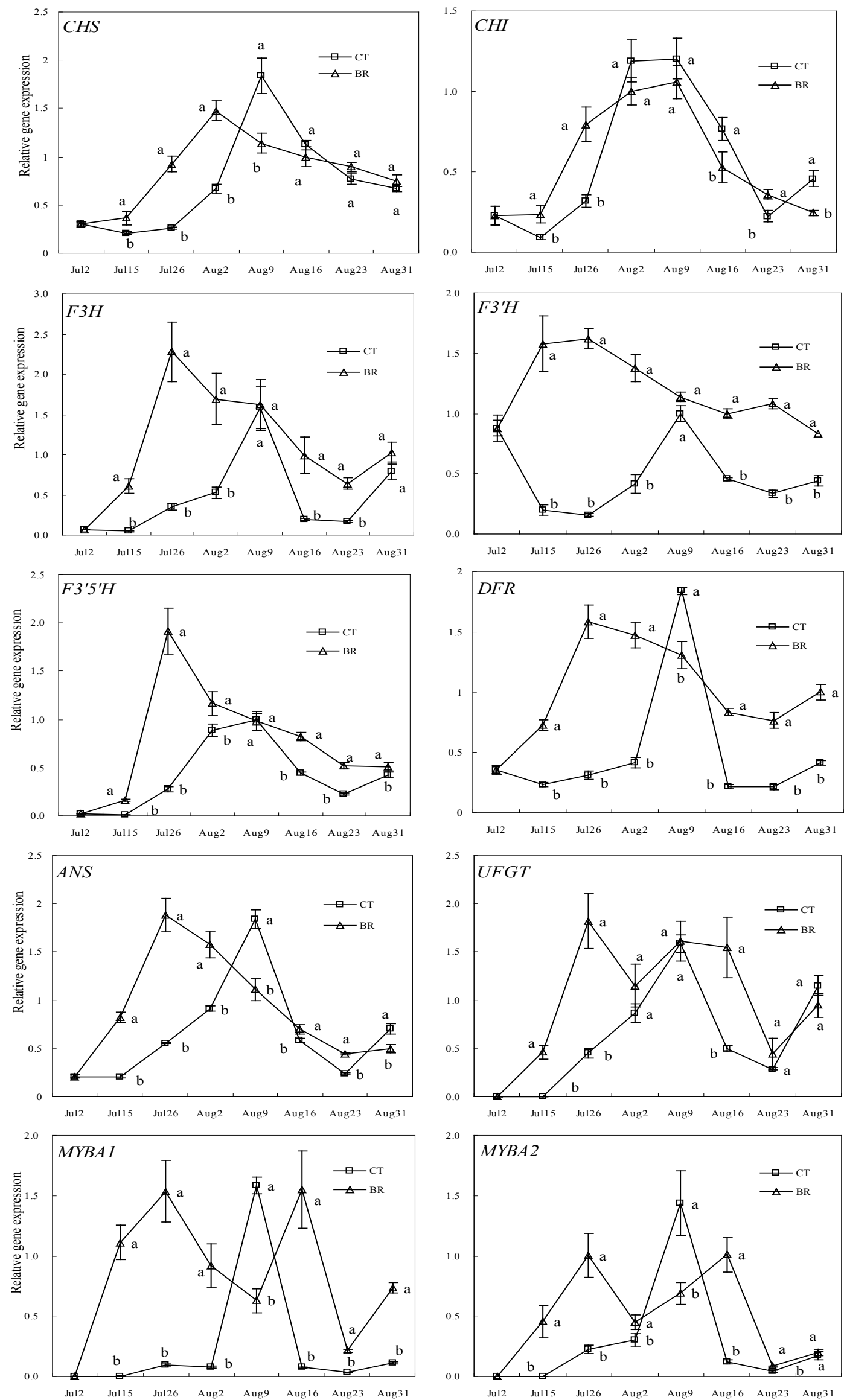

FIGURE 4.

Transcript profiling of structural genes and regulatory genes of anthocyanin biosynthesis in the skins of CT berries and BRtreated berries. Vertical bars represent standard deviation. Different letters ( $a$ and $b$ ) indicate significant differences at the 0.05 level by Duncan's test. 
The expression of upstream genes therefore is very important for anthocyanin biosynthesis. The range of advancement of full coloration may be limited by that of the expression of upstream genes ( $\mathrm{CHS}$ and $\mathrm{CHI})$ in BR-treated berries.

\section{$B R$ regulates anthocyanin biosynthesis}

Peng et al. (2011) showed that BR affected jasmonateinduced anthocyanin accumulation by regulating the 'late' anthocyanin biosynthesis genes (DFR, LDOX and UFGT). In our experiment, BR apparently also increased the expression of the downstream anthocyanin biosynthesis genes. Therefore, anthocyanin accumulation can be enhanced by up-regulated expression of the downstream anthocyanin biosynthesis genes.

\section{CONCLUSIONS}

This study evaluated the effect of exogenous BR applied to Cabernet Sauvignon clusters on the accumulation of anthocyanins and the gene expression of anthocyanin biosynthesis. The BR2 treatment $(0.4 \mathrm{mg} / \mathrm{L})$ significantly increased the content of soluble sugar and total anthocyanins, and resulted in full coloration seven days in advance. BR affected different tissues of the berry: skin cells (anthocyanin accumulation is restricted to) and berry flesh cells (sugar is accumulated in). The effect of BR on the downstream genes was more effective than on the upstream genes. The ranges of advancement of full coloration were limited to the expression of upstream genes $(\mathrm{CHI}$ and $\mathrm{CHS})$. Moreover, BR2 enhanced the transcript level of the downstream genes of anthocyanin biosynthesis, which caused an increase in total anthocyanin content. Structural and regulatory genes were induced under the BR treatment, which suggests that BR magnified the interrelationships between the developmental and environmental signalling pathways, which promoted fruit coloration.

The results from this study may help to gain an understanding of the control of fruit coloration and provide information for further research on the regulation mechanism, as well as on grape and wine qualities under the regulation of BRs.

\section{LITERATURE CITED}

Ban, T., Ishimaru, M., Kobayashi, S., Shiozaki, S., Goto-Yamamoto, N. \& Horiuchi, S., 2003. Abscisic acid and 2,4-dichlorophenoxyacetic acid affect the expression of anthocyanin biosynthetic pathway genes in 'Kyoho' grape berries. J. Hortic. Sci. Biotechnol. 78, 586-589.

Bitsch, R., Netzel, M., Frank, T., Strass, G. \& Bitsch, I., 2004. Bioavailability and biokinetics of anthocyanins from red grape juice and red wine. J. Biomed. Biotechnol. 293-298.

Bogs, J., Downey, M., Harvey, J., Ashton, A., Tanner, G. \& Robinson, S., 2005. Proanthocyanidin synthesis and expression of genes encoding leucoanthocyanidin reductase and anthocyanidin reductase in developing grape berries and grapevine leaves. Plant Physiol. 139, 652-663.

Bogs, J., Ebadi, A., Mcdavid, D. \& Robinson, S.P., 2006. Identification of the flavonoid hydroxylases from grapevine and their regulation during fruit development. Plant Physiol. 140, 279-291.

Borovsky, Y., Oren-Shamir, M., Ovadia, R., De Jong, W. \& Paran, I., 2004. The A locus that controls anthocyanin accumulation in pepper encodes a MYB transcription factor homologous to Anthocyanin2 of Petunia. Theor. Appl. Genet. 109, 23-29.
Boss, P.K. \& Davies, C., 2009 ( $2^{\text {nd }}$ ed). Molecular biology of anthocyanin accumulation in grape berries. In: Roubelakis-Angelakis, K.A. (ed). Grapevine molecular physiology \& biotechnology. Springer-Verlag, Berlin. pp. $263-292$.

Boss, P.K., Davies, C. \& Robinson, S.P., 1996a. Expression of anthocyanin biosynthesis pathway genes in red and white grapes. Plant Mol. Biol. 32, 565-569.

Boss, P.K., Davies, C. \& Robinson, S.P., 1996b. Analysis of the expression of anthocyanin pathway genes in developing Vitis vinifera L cv Shiraz grape berries and the implications for pathway regulation. Plant Physiol. 111, 1059-1066.

Boss, P.K., Davies, C. \& Robinson, S.P., 1996c. Anthocyanin composition and anthocyanin pathway gene expression in grapevine sports differing in berry skin colour. Aust. J. Grape Wine Res. 2, 163-170.

Castellarin, S.D., Pfeiffer, A., Sivilotti, P., Degan, M., Peterlunger, E. \& DI Gaspero, G., 2007a. Transcriptional regulation of anthocyanin biosynthesis in ripening fruits of grapevine under seasonal water deficit. Plant Cell Environ. 30, 1381-1399.

Castellarin, S.D., Matthews, M.A., Di Gaspero, G. \& Gambetta, G.A., 2007b. Water deficits accelerate ripening and induce changes in gene expression regulating flavonoid biosynthesis in grape berries. Planta 227, 101-112.

Davies, C. \& Böttcher, C., 2009 ( $2^{\text {nd }}$ ed). Hormonal control of grape berry ripening. In: Roubelakis-Angelakis, K.A. (ed). Grapevine molecular physiology \& biotechnology. Springer-Verlag, Berlin. pp. $229-261$.

Dufour, C. \& Sauvaitre, I., 2000. Interactions between anthocyanins and aroma substances in a model system. Effect on the flavor of grape-derived beverages. J. Agric. Food Chem. 48, 1784-1788.

El-kereamy, A., Chervin, C., Roustan, J.P., Cheynier, V., Souquet, J.M., Moutounet, M., Raynal, J., Ford, C., Latche, A., Pech, J.C. \& Bouzayen, M., 2003. Exogenous ethylene stimulates the long-term expression of genes related to anthocyanin biosynthesis in grape berries. Physiol. Plant 119, $175-182$.

GB/T 15038-2006, 2006. Analytical methods of wine and fruit wine. Standard Press, Beijing, China.

Goto-Yamamoto, N., Wan, G.H., Masaki, K. \& Kobayashi, S., 2002. Structure and transcription of three chalcone synthase genes of grapevine (Vitis vinifera). Plant Sci. 162, 867-872.

Holton, T.A. \& Cornish, E.C., 1995. Genetics and biochemistry of anthocyanin biosynthesis. The Plant Cell 7, 1071-1083.

Jeong, S.T., Goto-Yamamoto, N., Kobayashi, S. \& Esaka, A., 2004. Effects of plant hormones and shading on the accumulation of anthocyanins and the expression of anthocyanin biosynthetic genes in grape berry skins. Plant Sci. 167, 247-252.

Kobayashi, S., Goto-Yamamoto, N. \& Hirochika, H., 2004. Retrotransposoninduced mutations in grape skin color. Science 304, 982.

Kobayashi, S., Goto-Yamamoto, N. \& Hirochika, H., 2005. Association of VvmybA1 gene expression with anthocyanin production in grape (Vitis vinifera) skin-color mutants. J. Jpn. Soci. Hortic. Sci. 74, 196-203.

Kobayashi, S., Ishimaru, M., Hiraoka, K. \& Honda, C., 2002. Mybrelated genes of the Kyoho grape (Vitis labruscana) regulate anthocyanin biosynthesis. Planta 215, 924-933.

Liu, H.F., 2010. Cloning and expression of anthocyanin biosynthesis related structure genes in Vitis amurensis (in Chinese). Thesis, Northeast Forestry University, 26 Hexing Rd, Xiangfang, Harbin, Heilongjiang, China.

Meng, J.F., Fang, Y.L., Qin, M.Y., Zhuang, X.F. \& Zhang, Z.W., 2012. Varietal differences among the phenolic profiles and antioxidant properties of four cultivars of spine grape (Vitis davidii Foex) in Chongyi County (China). Food Chem. 134, 2049-2056. 
Mori, K., Sugaya, S. \& Gemma, H., 2005. Decreased anthocyanin biosynthesis in grape berries grown under elevated night temperature condition. Sci Hortic-Amsterdam. 105, 319-330.

Ozeki, Y., Chikagawa, Y., Kimura, S., Soh, H.C., Maeda, K., Pornsiriwong, W., Kato, M., Akimoto, H., Oyanagi, M., Fukuda, T., Koda, T., Itoh, Y. Yamada, A., Davies, E., Ueno, H. \& Takeda, J., 2003. Putative cis-elements in the promoter region of the carrot phenylalanine ammonia-lyase gene induced during anthocyanin synthesis. J. Plant Res. 116, 155-159.

Passamonti, S., Vrhovsek, U., Vanzo, A. \& Mattivi, F., 2005. Fast access of some grape pigments to the brain. J. Agr. Food Chem. 53, 7029-7034.

Peng, Z.H., Han, C.Y., Yuan, L.B., Zhang, K., Huang, H.M. \& Ren, C.M., 2011. Brassinosteroid enhances jasmonate-induced anthocyanin accumulation in Arabidopsis seedlings. J. Integr. Plant Biol. 53, 632-640.

Quiroga, A.M., Berli, F.J., Moreno, D., Cavagnaro, J.B. \& Bottini, R., 2009. Abscisic acid sprays significantly increase yield per plant in vineyardgrown wine grape (Vitis vinifera L.) cv. Cabernet Sauvignon through increased berry set with no negative effects on anthocyanin content and total polyphenol index of both juice and wine. J. Plant Growth Regul. 28, 28-35.

Ramsay, N., Walker, A., Mooney, M. \& Gray, J., 2003. Two basic-helixloop-helix genes (MYC-146 and GL3) from Arabidopsis can activate anthocyanin biosynthesis in a white-flowered Matthiola incana mutant. Plant Mol. Biol. 52, 679-688.

Reid, K.E., Olsson, N., Schlosser, J., Peng, F. \& Lund, S.T., 2006. An optimized grapevine RNA isolation procedure and statistical determination of reference genes for real-time RT-PCR during berry development. BMC Plant Biol. 6, 27.

Robbins, M., Paolocci, F., Hughes, J., Turchetti, V., Allison, G., Arcioni, S., Morris, P. \& Damiani, F., 2003. Sn, a maize bHLH gene, modulates anthocyanin and condensed tannin pathways in Lotus corniculatus. J. Exp. Bot. 54, 239-248.

Sainz, M., Grotewold, E. \& Chandler, V., 1997. Evidence for direct activation of an anthocyanin promoter by the maize $\mathrm{C} 1$ protein and comparison of DNA binding by related Myb domain proteins. Plant Cell 9, 611-625.
Schwinn, K., Venail, J., Shang, Y., Mackay, S., Alm, V., Butelli, E., Oyama, R., Bailey, P., Davies, K. \& Martin, C., 2006. A small family of MYB regulatory genes controls floral pigmentation intensity and patterning in the genus Antirrhinum. Plant Cell 18, 831-851.

Sinilal, B., Ovadia, R., Nissim-Levi, A., Perl, A., Carmeli-Weissberg, M. \& Oren-Shamir, M., 2011. Increased accumulation and decreased catabolism of anthocyanins in red grape cell suspension culture following magnesium treatment. Planta 234, 61-71.

Sparvoli, F., Martin, C., Scienza, A., Gavazzi, G. \& Tonelli, C., 1994. Cloning and molecular analysis of structural genes involved in flavonoid and stilbene biosynthesis in grape (Vitis vinifera L.). Plant Mol. Biol. 24 743-755.

Spelt, C., Quattrocchio, F., Mol, J. \& Koes, R., 2000. Anthocyanin1 of petunia encodes a basic helix-loop-helix protein that directly activates transcription of structural anthocyanin genes. Plant Cell 12, 1619-1631.

Symons, G.M., Davies, C., Shavrukov, Y., Dry, I.B., Reid, J.B. \& Thomas, M.R., 2006. Grapes on steroids. Brassinosteroids are involved in grape berry ripening. Plant Physiol. 140, 150-158.

Tang, H.L., 2009. The quality analyzed grape \& wine from origin producing area in MaNaSi county of XinJiang province (in Chinese). Thesis, Northwest A\&F University, 26 Hexing Rd, Xiangfang, Harbin, Heilongjiang, China.

This, P., Lacombe, T., Cadle-Davidson, M. \& Owens, C.L., 2007. Wine grape (Vitis vinifera L.) color associates with allelic variation in the domestication gene VvmybA1. Theor. Appl. Genet. 114, 723-730.

Vardhini, B.V. \& Rao, S.S.R., 2002. Acceleration of ripening of tomato pericarp discs by brassinosteroids. Phytochem. 61, 843-847.

Walker, A.R., Lee, E., Bogs, J., Mcdavid, D.A., Thomas, M.R. \& Robinson, S.P., 2007. White grapes arose through the mutation of two similar and adjacent regulatory genes. Plant J. 49, 772-785.

Winkel, B.S.J., 2006. The biosynthesis of flavonoids. In: Grotewold, E. (ed). The science of flavonoids. Springer-Verlag, Berlin. pp. $71-95$. 